\title{
Intoxicação espontânea pelas larvas de Perreyia flavipes em bovinos no Estado de Santa Catarina, Brasil
}

\author{
Spontaneous poisoning by larvae of Perreyia flavipes in cattle \\ from the State of Santa Catarina, Brazil
}

\author{
Djeison Lutier Raymundo ${ }^{\mathrm{I}}$ Pedro Soares Bezerra Junior ${ }^{\mathrm{I}}$ Paulo Mota Bandarra ${ }^{\mathrm{I}}$ \\ Adriana Silva dos Santos ${ }^{\mathrm{I}}$ Luciana Sonne ${ }^{\mathrm{I}}$ Saulo Petinatti Pavarini ${ }^{\mathrm{I}}$ \\ André Mendes Ribeiro CorrêaI Marcelo Maronna Dias ${ }^{\mathrm{II}}$ \\ David Driemeier $^{\mathrm{I}^{*}}$
}

RESUMO

Neste trabalho, é descrito um surto de intoxicação por Perreyia flavipes ocorrido em agosto de 2006, em um rebanho bovino de 280 animais, no município de Sombrio, em Santa Catarina. Ocorreram 17 mortes em um lote de 77 bovinos de raça mista com idades entre um e dois anos mantidos em um piquete ( $P 1)$ de aproximadamente 90 hectares por cerca de 30 dias. Após as primeiras duas mortes, os animais foram movidos para um segundo piquete $(\mathrm{P} 2)$, onde ainda ocorreram 15 mortes nos cinco dias após a transferência. Seis bovinos foram necropsiados, e amostras de tecidos foram avaliadas para exame histológico. Os achados de necropsia incluíam hemorragias subcutâneas na mucosa do abomaso e superfície subepicárdica. Ascite e edema do abomaso, duodeno, pâncreas e vesícula biliar foram observados. O fígado apresentava-se amarelado com petéquias subcapsulares $e$ acentuação do padrão lobular. No rúmen de três bovinos, foram encontrados fragmentos de corpos e cabeças de larvas de $\boldsymbol{P}$. flavipes em meio ao conteúdo ruminal. Histologicamente o fígado apresentava tumefação hepatocelular e necrose centrolobular e mediozonal, difusa e acentuada, com hemorragia e congestão centrolobular. Havia depleção e necrose linfóide no baço, placas de Peyer e linfonodos mesentéricos. O diagnóstico de intoxicação pelas larvas da $\boldsymbol{P}$. flavipes foi baseado nos dados epidemiológicos, nos achados de necropsia e nas alterações histopatológicas. As lesões hepáticas e em tecidos linfóides, além da grande quantidade de larvas de $\boldsymbol{P}$. flavipes no primeiro piquete $(P 1)$ e no rúmen de animais necropsiados, foram dados importantes para o diagnóstico.

Palavras-chave: Perreyia flavipes, necrose de fígado, bovinos.

\section{ABSTRACT}

This article describes an outbreak of Perreyia flavipes poisoning in August of 2006 in a cattle herd of 280 animals in Sombrio, Santa Catarina, southern Brazil. Seventeen bovines between 1 and 2 years old from one herd of 77 mixed breed cattle died. The herd was kept in a paddock of 90 hectares (P1) for 30 days. After de first two deaths occurred, the herd was transferred to a second paddock (P2), and 15 more animals died in the next 5 days. Samples from 6 of these animals were analyzed. During the necropsy, hemorrhage was seen in the subcutaneous tissue, abomasal mucosa, and subepicardial area. The animals presented ascites and edema of the abomasal folds, duodenum, pancreas, and gallbladder. The liver was yellowish, had subcapsular petechial hemorrhages, and accentuated lobular pattern. P. flavipes larval body fragments and heads were found in the rumen content of three of the animals. In the histological examination the liver showed hepatocellular tumefaction, diffuse coagulative necrosis of centrilobular and midzone hepatocytes, hemorrhage and centrilobular congestion. Lymphoid depletion and diffuse necrosis of germinative centers of lymphoid follicles in mesenteric lymph nodes, Peyer's patches and spleen were also observed. The diagnosis of intoxication by $\boldsymbol{P}$. flavipes larvae in this outbreak was based on the epidemiological data, necropsy, and histological findings. The confirmation of $\boldsymbol{P}$. flavipes larvae as cause of the outbreak was done by the observation of intact larvae and remnants in the ruminal content of the necropsied bovines and by the presence of a great number of larvae clusters in the paddock 1 (P1).

Key words: Perreyia flavipes, liver necrosis, cattle, sawfly.

\section{INTRODUÇÃO}

Larvas da subordem Symphyta (Sawfly) são descritas em diferentes países do mundo como responsáveis por intoxicações hepáticas agudas em

ISetor de Patologia Veterinária (SPV), Universidade Federal do Rio Grande do Sul (UFRGS). Av. Bento Gonçalves, 9090, Agronomia, 91540-000, Porto Alegre, RS, Brasil. E-mail: davetpat@ufrgs.br. *Autor para correspondência.

"IAutônomo, Porto Alegre, RS, Brasil. 
diversas espécies de animais domésticos. Na Austrália, as larvas da Lophyrotoma interrupta (Pergidae) causaram mortalidade em bovinos e ovinos (MCKENZIE et al., 1985). Na Dinamarca, ocorreu mortalidade por larvas da Arge pullata (Argidae) em ovinos e caprinos (THAMSBORG et al., 1987).

Na região Sul do Brasil, existem relatos de intoxicações em suínos pela ingestão das larvas de Perreyia lepida pertencente à família Pergidae (CAMARGO, 1955). A intoxicação natural pelas larvas da $\boldsymbol{P}$. flavipes foi descrita em bovinos no Uruguai (DUTRA, 1997) e no Rio Grande do Sul (SOARES et al., 2008). Experimentalmente, as larvas se mostraram tóxicas para suínos na dose de $10 \mathrm{~g} \mathrm{~kg}^{-1}$ (SOARES et al. 2001), bovinos na dose de $40 \mathrm{~g} \mathrm{~kg}^{-1}$ (DUTRA,1997) e ovinos na dose de $7,5 \mathrm{~g} \mathrm{~kg}^{-1}$ (RAYMUNDO, 2008).

Foram isolados das larvas de $\boldsymbol{P}$. flavipes, $\boldsymbol{A}$. pullata e $\boldsymbol{L}$. interrupta dois diferentes $\mathrm{D}$-aminoacidos peptídicos denominados de lofirotomina e pergidina, ambos com efeito hepatotóxico comprovado e responsáveis pelas mortes em intoxicações pelas larvas das sawfly. (OELRICHS et al., 1977; OELRICHS et al. 1999).

Este trabalho descreve os aspectos clínicos e patológicos de um surto de intoxicação natural por larvas de $\boldsymbol{P}$. flavipes em bovinos, ocorrido no Estado de Santa Catarina.

\section{MATERIAL E MÉTODOS}

Os dados epidemiológicos e sinais clínicos da doença foram obtidos junto ao proprietário e aos funcionários do estabelecimento. Foram recebidas, no Setor de Patologia Veterinária (SPV), amostras de tecido fixadas em formalina $10 \%$ e material refrigerado referente à necropsia de três bovinos . Foi solicitada ao SPV uma visita à propriedade onde foram necropsiados mais três animais. Amostras de fígado, rim, baço, coração, pulmão, linfonodos, encéfalo, intestinos e próventrículos foram coletadas na necropsia, fixadas em formalina $10 \%$ tamponada, processadas com as técnicas histológicas de rotina e corados com Hematoxilina e Eosina.

\section{RESULTADOS E DISCUSSÃO}

A propriedade visitada está localizada no município de Sombrio, em Santa Catarina. As mortes ocorreram em agosto de 2006, em um rebanho de 280 animais. Morreram 17 bovinos de um lote de 77 animais de raça mista, entre um e dois anos de idade, alocados em um piquete de aproximadamente 90 hectares (P1). Os bovinos permaneceram nesse piquete por um período de 30 dias . Eles se alimentavam de pastagem nativa e não recebiam nenhum tipo de suplementação mineral ou complemento alimentar. Dois animais foram encontrados mortos no P1 e outros apresentaram fezes muito secas. Por suspeita de intoxicação, os animais foram transferidos para outro piquete (P2). No P2, morreram mais 15 bovinos num período de cinco dias após a transferência e depois disso as mortes cessaram. No P1, foram encontrados inúmeros agrupamentos das larvas de $\boldsymbol{P}$. flavipes em meio à pastagem (Figura 1A). Não foram encontradas plantas de potencial hepatotóxico reconhecido e nem plantas da espécie Baccharis spp. em nenhum dos piquetes (P1 e P2). Os animais eram observados pelos responsáveis uma vez ao dia, e nenhum animal doente foi detectado.

No total, seis bovinos foram necropsiados e estavam em bom estado nutricional. Na abertura da carcaça, foram observadas hemorragias na forma de petéquias e sufusões, no tecido subcutâneo. Os bovinos apresentavam ascite e edema na região do abomaso, do duodeno, do pâncreas e da vesícula biliar. Na superfície subpericárdica e na mucosa do abomaso, havia equimoses e sufusões. Na porção final do cólon, no ceco e no reto, o material fecal apresentava-se ressecado e com pequena quantidade de muco.

$\mathrm{O}$ fígado apresentava-se amarelado com hemorragias petequiais distribuídas de forma aleatória no parênquima e acentuação do padrão lobular tanto na superfície capsular como ao corte, caracterizada por áreas vermelho-escuras centrolobulares entremeados por áreas mais claras (Figura 1B). No rúmen de três bovinos necropsiados pela equipe do SPV, foram encontrados restos das larvas de $\boldsymbol{P}$. flavipes em meio ao conteúdo.

A principal lesão microscópica nos animais necropsiados foi observada no fígado, caracterizavase por necrose coagulativa da região centrolobular e mediozonal, difusa e acentuada (Figura 1C), com congestão, hemorragia e infiltrado mononuclear centrolobulares. Alterações periportais incluíam tumefação e vacuolização hepatocelular, necrose individual de hepatócitos e raras inclusões eosinofílicas circulares no citoplasma de hepatócitos, caracterizando alterações degenerativas citoplasmáticas

Na polpa branca do baço, nos linfonodos, nas tonsilas, nas placas de Peyer e nos nódulos linfóides do intestino grosso, foram observadas depleção linfóide e necrose difusa e acentuada de centros germinativos (Figura 1D).

O diagnóstico de intoxicação pelas larvas da $\boldsymbol{P}$. flavipes desse surto foi baseado nos dados epidemiológicos, nos achados de necropsia e nas alterações histopatológicas. Havia grande quantidade 


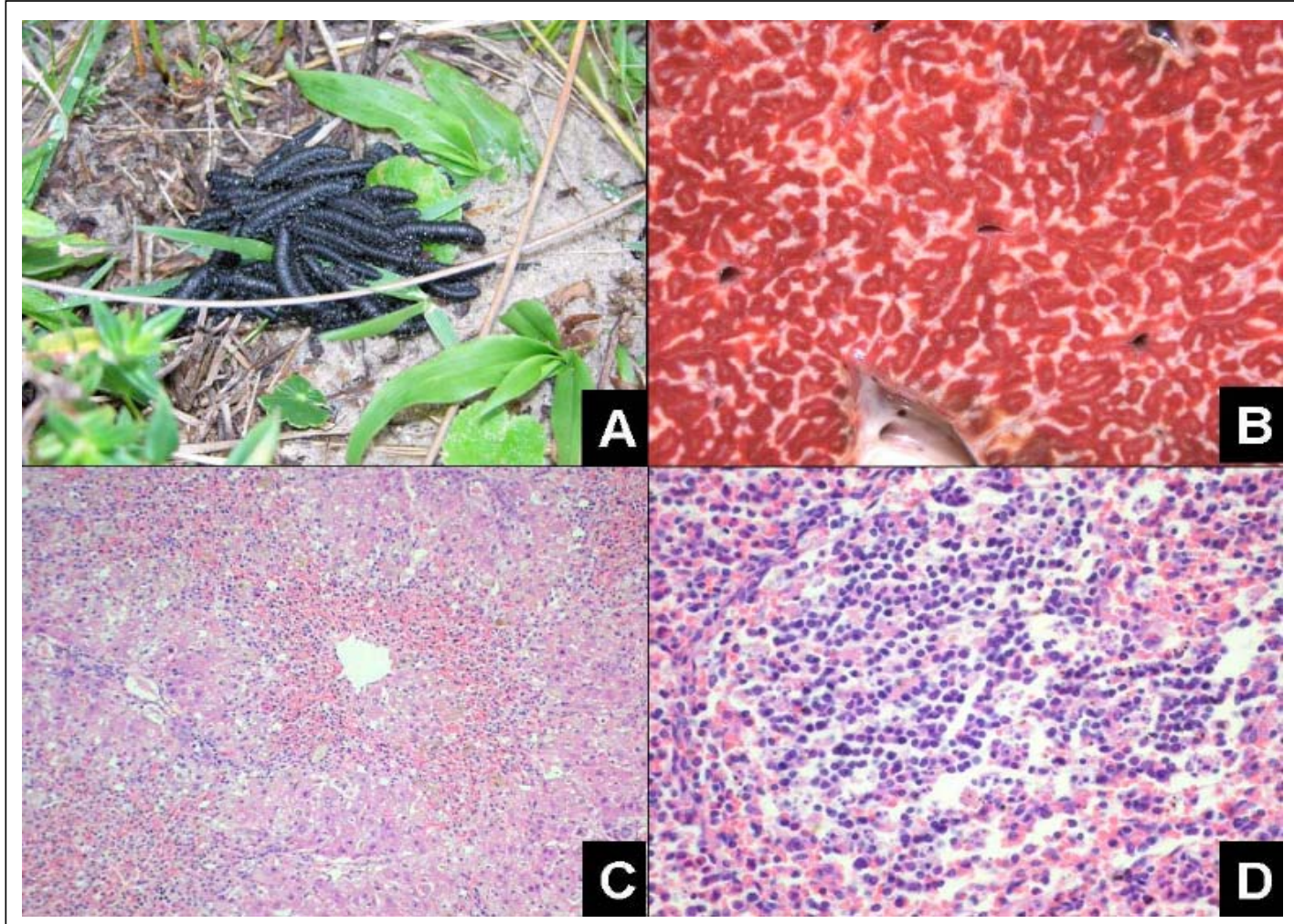

Figura 1 - Bovino, misto. Intoxicação por larvas de Perreyia flavipes. A) Agrupamento de larvas de $\boldsymbol{P}$. flavipes em meio à pastagem. B) Fígado com aumento do padrão lobular na superfície de corte. C) Fígado com necrose de coagulação centrolobular e mediozonal, difusa, acentuada com congestão e hemorragia centrolobulares e hepatócitos da região periportal tumefeitos e vacuolizados. HE, obj 20. D) Baço, polpa branca com depleção linfóide e necrose difusa e acentuada de centros germinativos. HE, obj 40.

de larvas agrupadas em diferentes locais do campo onde os primeiros bovinos foram encontrados mortos. A presença de partes de larvas e larvas íntegras misturadas ao conteúdo ruminal dos bovinos necropsiados corrobora o diagnóstico. As mortes começaram no piquete 1 e perduraram por cinco dias após a introdução no piquete 2 . A evolução da mortalidade indica que a intoxicação ocorreu no piquete 1 , já que no piquete 2 não foram encontradas larvas de P. flavipes nem outra causa reconhecida de hepatotoxicidade aguda.

Ocorreram outros surtos de intoxicação pelas larvas de $\boldsymbol{P}$. flavipes em bovinos (SOARES et al., 2008) e ovinos (RAYMUNDO et al., 2008) no mesmo período no Rio Grande do Sul. SOARES et al. (2008) relacionaram o aumento do número de larvas de $\boldsymbol{P}$. flavipes no ambiente e, conseqüentemente, os surtos de intoxicação, à baixa precipitação pluviométrica no final do ano de 2005 e à alta precipitação no início de 2006.

Os achados de necropsia e histopatologia são semelhantes aos encontrados em outras causas de intoxicações hepáticas agudas em bovinos. No diagnóstico diferencial, devem ser incluídas as plantas Cestrum corymbosum var. hirsutum (GAVA et al., 1991), Cestrum intermedium (GAVA et al., 1996), Cestrum laevigatum (DÖBEREINER et al., 1969), Cestrum parqui (RIET-CORREA et al., 1986), Dodonea viscosa (COLODEL et al., 2003), Myoporum Iaetum (RAPOSO et al., 1998), Sessea brasiliensis (CANELLA et al., 1968), Trema micrantha (TRAVERSO et al., 2004), Vernonia mollissima (DÖBEREINER et al., 1976), Vernonia rubricaulis (TOKARNIA et al., 1982), Xanthium cavanillessi (DRIEMEIER et al., 1999; ).

As lesões necróticas dos centros germinativos de órgãos linfóides observadas na histopatologia são de grande valia na diferenciação de casos de intoxicação por outras hepatotoxicoses agudas (MCKENZIE et al., 1985). Alterações necróticas de centros germinativos de órgãos linfóides podem ser observadas em casos de intoxicações por Polygala klotzschii, Baccharis coridifolia, B. megapotamica var. megapotamica, B. megapotamica var. weirii, Ricinus communis, e Schultesia guianensis (TOKARNIA et al., 2000); entretanto, não têm sido

Ciência Rural, v.39, n.1, jan-fev, 2009. 
descritas em casos de intoxicações que cursem com necrose hepática aguda.

\section{CONCLUSÕES}

Os dados do presente trabalho indicam que as larvas de $\boldsymbol{P}$. flavipes devem ser consideradas no diagnóstico diferencial sempre que lesões de necrose hepática são encontradas em bovinos nas áreas de ocorrência dessas larvas. O diagnóstico diferencial das plantas hepatotóxicas pode ser feito pela comprovação da presença das larvas de $\boldsymbol{P}$. flavipes em meio ao conteúdo ruminal. A depleção e a necrose em centros germinativos do baço, linfonodos, e placas de Peyer, associadas às lesões necróticas no fígado, são grandes indicativos de intoxicação pelas larvas de $\boldsymbol{P}$. flavipes. As mortes ocorridas no segundo piquete (P2) foram atribuídas à ingestão de larvas no Piquete 1 (P1), com manifestação da toxicidade após a remoção do piquete afetado.

\section{REFERÊNCIAS}

CAMARGO, O.R. Contribuição ao estudo do Tenthredinideo Mata Porcos, Paraperreyia dorsuaria (Know, 1899), no Rio Grande do Sul. 1955. 29f. Tese (Doutorado em Agronomia) - Escola de Agronomia e Veterinária da Universidade Federal do Rio Grande do Sul.

CANELLA, C.F.C. et al. Intoxicação por Sessea brasiliensis Toledo em bovinos. Pesquisa Agropecuária Brasileira, v.3, p.333-340, 1968.

COLODEL, E.M. et al. Spontaneous poisoning by Dodonea viscosa (Sapindadeae) in cattle. Veterinary and Human Toxicology, v.45,n.3, p.148, 2003.

DRIEMEIER, D. et al. Intoxicação espontânea pelos frutos de Xanthium cavanillesii (Asteraceae) em bovinos no Rio Grande do Sul. Pesquisa Veterinária Brasileira, v.19, n.1, p.1218, 1999.

DÖBEREINER, J. et al. Intoxicação por Cestrum laevigatum Schlecht., a causa de mortandades em bovinos no estado do Rio de Janeiro. Pesquisa Agropecuária Brasileira, v.4, p.165193, 1969.

DÖBEREINER, J. et al. Vernonia mollissima, planta tóxica responsável por mortandades de bovinos no sul de Mato Grosso. Pesquisa Agropecuária Brasileira, v.11, p.49-58, 1976.

DUTRA, F. Intoxicação por larvas de Perreyia flavipes. Caracterização da doença e biologia do inseto. 1997. 46f. Dissertação (Mestrado em Veterinária) - Curso Pósgraduação em Sanidade Animal, Faculdade de Veterinária da Universidade Federal de Pelotas.
GAVA, A. et al. Intoxicação por Cestrum corymbosum var. hirsutum (Solanaceae) em bovinos no Estado de Santa Catarina. Pesquisa Veterinária Brasileira, v.11, n.3/4, p.71-74, 1991.

GAVA, A. et al. Intoxicação por Cestrum intermedium (Solanaceae) em bovinos. Pesquisa Veterinária Brasileira, v.16, n.4, p.117-120, 1996.

MCKENZIE, R.A. et al. Sawfly larvae poisoning of cattle in Queensland. In: SEAWRIGHT, A.A. et al. (Eds). AUSTRALIAUSA POISONOUS PLANTS SYMPOSIUM, 1985, Brisbane. Proceedings... Brisbane, Australia: Queensland Poisonous Plants Committee, 1985. p.524-532.

OELRICHS, P. B. et al. Lophyrotomin, a new toxic octapeptide from the larvae of sawfly, Lophyrotoma interrupta. Lloydia, v.40, n.2, p.209-214, 1977.

OELRICHS, P. B. et al. Unique toxic peptides isolated from sawfly larvae in three continents. Toxicon, v.37, n.3, p.537544, 1999.

RAPOSO, J.B. et al. Experimental Intoxication by Myoporum laetum in cattle. Veterinary and Human Toxicology, v.40, n.5, p.275-277, 1998.

RAYMUNDO, D.L. Intoxicação espontânea por larvas de Perreyia flavipes (Pergidae) em ovinos e bovinos e intoxicação experimental em ovinos e coelhos. 2008. 69f. Dissertação (Mestrado em Veterinária) - Faculdade de Veterinária da Universidade Federal do Rio Grande do Sul.

RAYMUNDO, D.L. et al. Spontaneous poisoning by larvae of Perreyia flavipes (Pergidae) in sheep. Pesquisa Veterinária Brasileira, v.28, n.1, p.19-22, 2008.

RIET-CORREA, F. et al. Intoxicação por Cestrum parqui (Solanaceae) em bovinos no Rio Grande do Sul. Pesquisa Veterinária Brasileira, v.6, n.4, p.111-115, 1986.

SOARES, M.P. et al. Experimental intoxication by larvae of Perreyia flavipes Know, 1899 (Hymenoptera: Pergidae) in pigs and some aspects on its biology. Toxicon, v.39, n.5, p.669678, 2001.

SOARES, M.P. et al. Intoxicação por larvas de Perreyia flavipes Konow, 1899 (Hymenoptera: Pergidae) em bovinos na região sul do Rio Grande do Sul. Pesquisa Veterinária Brasileira, v.28, n.3, p.1690-173, 2008.

THAMSBORG, R.J. et al. Sawfly poisoning in sheep and goats. Veterinary Record, v.121, n.11, p. 253-255, 1987.

TOKARNIA, C.H.; DÖBEREINER, J. Intoxicação de bovinos por Vernonia rubricaulis (Compositae) em Mato Grosso. Pesquisa Veterinária Brasileira, v.2, n.4, p.143-147, 1982.

TOKARNiA, C.H. et al. Plantas tóxicas do Brasil. Rio de Janeiro: Helianthus, 2000. 310p.

TRAVERSO, S.D. et al. Intoxicação experimental por Trema micrantha (Ulmaceae) em bovinos. Pesquisa Veterinária Brasileira, v.24, n.4, p.211-216, 2004. 